\title{
Influência da natação como coadjuvante terapêutico no tratamento de crianças asmáticas
}

\author{
Gisele Pereira J acques ${ }^{1}$ e 0 sni J acó da Silva ${ }^{2}$
}

\begin{abstract}
RESUMO
0 presente estudo teve por objetivo investigar qual a influência da natação como coadjuvante terapêutico para crianças asmáticas na faixa etária de seis a 14 anos. Propôs-se a verificar se esta atividade física diminui a duração e a intensidade das crises e/ ou aumenta 0 intervalo das mesmas. Para tanto, foi realizada uma entrevista com as mães das crianças asmáticas que praticam natação. Foram realizadas ao todo 17 entrevistas em seis escolas de natação da llha de Santa Catarina. Para análise dos dados quantitativos, foi utilizada a estatística descritiva e as informações que precisaram de abordagens qualitativas foram tratadas através de análise interpretativa. Pelos dados obtidos no presente estudo, percebeu-se que a prática da natação aumenta o intervalo entre as crises, diminui sua duração, tendo havido melhora no grau de intensidade das mesmas. O utros resultados obtidos foram os seguintes: as crianças asmáticas adquirem mais resistência com a prática da natação; evidenciou-se também melhora nos aspectos psicológicos e sociais; e, mesmo que subjetivamente, foi percebido que, após a prática da natação, houve melhor eficácia da mecânica respiratória, conseqüentemente meIhor ventilação pulmonar e também reeducação respiratória.
\end{abstract}

\section{REVISÃO DA LITERATURA}

\section{Aspectos fisiopatológicos da asma}

De acordo com Marques(10), a asma é a causa mais comum de doença crônica durante a infância. 0 termo "asma" vem do grego "Asthma", que significa sufocação. É uma doença complexa, a qual não pode ser definida adequadamente em termos de um simples mecanismo fisiopatológico. Para o mesmo autor as duas definições aceitas universalmente são:

“a) Conceito de Scadding: 'Asma é uma doença caracterizada por uma ampla variação, por períodos variáveis de

1. Professora de Educação Física; Especialista em Exercício e Saúde - UFSC.

2. Professor Assistente IV da UFSC; Professor de Educação Física; Médico Especialista em Medicina Desportiva; Mestre em Bases Biomédicas.

Endereço para correspondência - U niversidade Federal de Santa Catarina, CDS-MDE, Trindade - 88049-900 - Florianópolis, SC. Fone para contatos: (048) $972-1770$.

\section{Influence of swimming as therapeutic adjuvant in the treatment of asthmatic children}

\section{ABSTRACT}

The purpose of this study is to investigate the influence of swimming as therapeutic adjuvant for asthmatic children from 6 to 14 years of age. The aim was to verify whether this physical activity would decrease both the duration and the intensity of crises and/or increase the crisis-free period. An interview was carried out with the mothers of asthmatic children who swin. 17 interviews were done in 6 swimming schools in Santa Catarina Island. Descriptive statistics was used to analyze quantitative data, and interpretation analysis was used for qualitative information. Results of such analysis showed that swimming does increase the crisis-free period, decreases crisis duration, and an improvement was seen in the degree of severity of the crises. Other results obtained were the following: asthmatic children develop more resistance with swimming; psychological and social improvements were also observed; even if subjectively, observations al so showed a more effective mechanical ventilation after swimming, which leads to improved pulmonary ventilation and to respiratory reeducation. 
tempo, na resistência ao fluxo de ar nas vias aéreas intrapulmonares'.

“b) Conceito da 'American Thoracic Society': 'A sma é uma doença caracterizada por uma hiperatividade de traquéia e brônquios a vários estímulos, manifestando-se por um estreitamento generalizado das vias aéreas que modifica em gravidade, espontaneamente ou como resultado do tratamento'." (pag. 1).

De acordo com Teixeira et al.(20), a asma representa uma obstrução difusa das vias aéreas, reversível espontaneamente ou com o tratamento. Fisiologicamente é uma obstrução de vias aéreas associadas e farmacologicamente é a reatividade exagerada das vias aéreas a estímulos específicos e inespecíficos.

Hiper-reatividade brônquica consiste em desequilíbrio do mecanismo que determina o diâmetro interno do brônquio, que é dependente do tônus da musculatura lisa da árvore respiratória, da espessura da mucosa e da quantidade de secreção presente na luz brônquica ${ }^{(14,19)}$.

De acordo com Nolte ${ }^{(14)}$, o organismo do indivíduo asmático elabora uma substância responsável por uma série de reações, entre elas a contração da musculatura lisa que reveste o brônquio. Isso provoca estreitamento bronquiolar (broncoespasmo) durante a fase da expiração, ocasionando o "chiado" e sensação de falta de ar. Este quadro, associado ao acúmulo de catarro e tosse, é caracterizado por "crise asmática".

Segundo Teixeira et al.(19), estes fatores provocam aumento da resistência das vias aéreas, distribuição irregular do ar inspirado, distúrbios na relação ventilação-perfusão e maior consumo energético durante o trabalho respiratório.

As crises asmáticas podem ter duração de horas ou dias e períodos sem sintomas de dias/ meses. A dispnéia é predominantemente expiratória e decorrente dos fatores acima apontados. Destes fatores, o broncoespasmo parece ser 0 mais importante(20).

De acordo com Negreiros(11), os fatores etiológicos foram agrupados em duas categorias: extrínsecos, quando relacionados a alergia por produtos do meio ambiente, e intrínsecos, quando devidos à sensibilidade às bactérias do meio interno dos pacientes. 0 mesmo autor ainda faz outra classificação: os relacionados aos mecanismos imunológicos (asma alérgica) e aqueles nos quais estes mecanismos não são evidenciados (asma não alérgica).

São reconhecidos vários graus de gravidade da asma na infância. Conforme Dinwiddie(4), é útil dividi-la em três graus: a) asma esporádica leve, com menos de um ataque a cada dois meses (75\% das crianças asmáticas); b) asma episódica freqüente, ou moderada, com mais de um ataque a cada dois meses ( $20 \%$ das crianças asmáticas); e c) asma severa crônica com sintomas diurnos e noturnos persistentes, limitação da atividade física e anormalidades persistentes da função pulmonar ( $5 \%$ das crianças asmáticas).

\section{Causas}

Diversos são os agentes desencadeadores de crises asmáticas; segundo Lapierre(9), existe provavelmente predisposição hereditária que pode ou não causar a crise.

Freqüentemente a causa é de origem alérgica(14), mas outros agentes podem estar presentes. Muitas vezes 0 asmático pode ser alérgico a certa substância, porém as crises podem ser determinadas também por diversos agentes tais como infecciosos, emocionais, ou ainda, até mesmo uma mudança de temperatura ambiental. Torna-se difícil muitas vezes detectar o fator primordial(13). Testes alérgicos podem ser realizados, apesar de seu papel não estar claramente definido(8).

Classificam-se os diferentes agentes segundo a sua origem em:

a) Alérgenos: 1) inalantes: pó doméstico (presença de ácaro dermatofagóide), fungos, epitélio de animais (pêlos e penas), piretro (substância utilizada para fixação de perfumes), lã, lírio florentino, paina e capim; 2) alimentos: leite e derivados, chocolate, abacaxi, alho, cebola; 3) medicamentos: antiinflamatórios não hormonais (ácido acetilsalicílico, p. ex.);

b) Irritantes: poluentes ambientais, variações climáticas bruscas, fumaça de cigarro, desinfetantes domiciliares, inseticidas, ceras, perfumes de ambientes, fumaça oriunda de fábricas, derivados de petróleo e outros;

c) Infecciosos: infecções virais, como por exemplo um resfriado comum;

d) Emocionais: nestes incluídas a insegurança, a timidez, as emoções fortes, as reações a novas situações(13);

e) Exercício físico: causa muito discutida pelos estudiosos do assunto é a asma induzida pelo exercício (AIE).

\section{Alterações provocadas pela doença}

As conseqüências de repetidas crises de asma não afetam somente o próprio portador da doença, mas também o restante da família. Pode-se classificá-las como:

a) Conseqüências fisiológicas - De acordo com Nolte ${ }^{(14)}$, a asma crônica pode evoluir, passando para um enfisema pulmonar. Neste caso, os pulmões não têm mais capacidade de recuperar o estado de hiperinsuflação, passando a ocorrer inclusive alterações na troca gasosa. 0 mesmo autor ainda cita, como seqüela da asma crônica grave, a insuficiência cardíaca devida a maior sobrecarga do ventrículo direito;

b) Conseqüências psicológicas - Conforme Nieto(13), configuram-se como insegurança, timidez e agressividade;

c) Conseqüências familiares e sociais - Ainda de acordo com Nieto(13), a constante ida a prontos-socorros acaba desestruturando toda a família. O s gastos com medicamentos, consultas e hospitalizações muitas vezes superam a renda familiar. Muitas crianças perdem o ano escolar devido a constantes faltas às aulas; 
d) Conseqüências morfológicas - São caracterizadas pelas deformidades, principalmente as de tórax. Segundo Azeredo(1), o asmático, pela dificuldade em respirar (principalmente em expirar), acaba por utilizar a musculatura acessória da respiração, ou seja, a de colo e pescoço. 0 tórax em estado de hiperinsuflação mobiliza-se pouco. Nieto ${ }^{(13)}$ cita como exemplo de deformidades o "peito de pombo", depressão submamária, hemitórax, cifose dorsal e horizontalização das costelas.

\section{ATIVIDADE FÍSICA E A CRIANÇA ASMÁTICA}

Durante certo tempo a atividade física foi negligenciada e até mesmo negada nas escolas a portadores de asma.

De acordo com Teixeira( ${ }^{(20)}$, o asmático crônico está freqüentemente em precária condição física causada por inatividade, apresentando inclusive um subdesenvolvimento físico.

As possíveis razões para que antigamente se evitassem as atividades físicas eram o broncoespasmo produzido por exercícios intensos e a superproteção. No entanto, as atividades físicas são necessárias para o desenvolvimento harmônico do indivíduo (13).

Para Grumach e Teixeira(6), o exercício se tornou um dos recursos preventivos da doença, mas deve ser ministrado apenas no período intercrise, pois os benefícios de prevenção das crises ocorrem exatamente nesta fase.

Segundo Marques ${ }^{(10)}$, os exercícios de relaxamento e respiração podem ajudar as crianças que não estão fisicamente bem condicionadas. Permite que elas respirem mais facilmente, fornecendo melhores condições contráteis para a musculatura respiratória. Também ajudam a reduzir a ansiedade nas crises agudas. Para o mesmo autor, a natação e os jogos com fase de intervalo são particularmente úteis, porque parece ser o esporte que as crianças com asma podem executar com menor possibilidade de induzir crise. Esses exercícios melhoram a aptidão física geral, estimulam a autoconfiança e promovem a socialização.

De acordo com Grumach e Teixeira(6), é preciso considerar ainda 0 aspecto psicológico do exercício, porque muitas vezes 0 adulto, ou a criança asmática, sente-se marginalizado por não poder andar descalço, entrar numa piscina, etc. Para estes autores, as crianças e os adultos que compartiIham naturalmente os exercícios com outros indivíduos ganham muito bem-estar físico e psicológico.

\section{Natação}

A natação é reconhecida como a atividade física menos asmagênica que os demais exercícios ${ }^{(14)}$.

$\mathrm{Na}$ natação, o ar inalado é mais quente e úmido; este é um dos fatores por que esta atividade física provoca menos broncoespasmo ${ }^{(12,17,18)}$, sendo, portanto, o exercício mais recomendado pelos médicos e outros profissionais de saúde.
Segundo Nieto(13), os objetivos mais importantes da natação são vistos sob três aspectos: físico, orgânico e psicológico. 0 primeiro visando o desenvolvimento das qualidades físicas, relaxamento, controle respiratório e corporal e as habilidades aquáticas. 0 segundo, 0 desenvolvimento da resistência do sistema muscular, resistência do sistema cardiovascular, respiratório e expansão pulmonar. E o terceiro, desenvolvimento da autoconfiança e criatividade, equilíbrio emocional e consciência corporal.

Para Teixeira(20), a natação contribui para fortalecer todos os músculos, especialmente o diafragma e os músculos respiratórios auxiliares. 0 mesmo autor cita como vantagens a posição horizontal do corpo e os movimentos de braços que facilitam a expansibilidade torácica, favorecendo a tomada de ar. A respiração submersa encontra na água uma resistência ideal para manter por muito tempo a abertura dos brônquios, evitando o fenômeno de "ar retido". A reeducação da mecânica respiratória também pode ser obtida. A lém disso, evita o ressecamento das vias aéreas, devido à respiração de ar mais úmido no ambiente próximo à piscina.

O liveira(15) cita, também, que a natação proporciona meIhora na função respiratória, através de exercícios de ventilação pulmonar localizada, reeducação diafragmática, fortalecimento da musculatura respiratória e corporal geral, prevenção de alterações ósseas da coluna vertebral e torácica.

$\mathrm{Na}$ natação, a ventilação pulmonar deve ser mais eficiente e por isso deve-se trabalhar a resistência aeróbica, tornando o asmático capaz de suportar um esforço de longa duração numa intensidade moderada. Este trabalho virá aumentar a capacidade ventilatória pulmonar(13).

Conforme Oliveira(15), existem crianças asmáticas cujas crises, com a prática da natação, tendem a diminuir, podendo até mesmo desaparecer.

\section{APRESENTAÇÃO E DISCUSSÃO DOS RESULTADOS}

Antes de abordar os resultados, deixa-se bem claro que neste estudo não houve parâmetros laboratoriais, como a utilização dos testes de função pulmonar, que são necessários para o diagnóstico e avaliação da gravidade e evolução do quadro asmático.

\section{Dados pessoais}

TABELA 1

Caracterização dos sujeitos segundo faixa etária e sexo

\begin{tabular}{lccrl}
\hline Faixa etánia & Feminino & Masculino & Total \\
& & $3(25,0 \%)$ & 3 & $(17,7 \%)$ \\
$6-8$ anos & & $5(41,7 \%)$ & $10(58,8 \%)$ \\
$9-11$ anos & $5(100 \%)$ & $4(33,3 \%)$ & $4(23,5 \%)$ \\
$12-14$ anos & & $12(100 \%)$ & $17(100 \%)$ \\
\hline Total & $5(100 \%)$ & & \\
\hline
\end{tabular}




\section{TABELA 2}

Motivo pelo qual a criança iniciou a prática da natação

\section{Motivo}

- Devido à asma

Freqüência

- Devido à asma e a outros

$11(64,7 \%)$

problemas, como: postural e crescimento

$4(23,5 \%)$

- Praticar alguma atividade física

$2(11,8 \%)$

e aprender a nadar

Total

$17(100 \%)$

A nalisando a tabela 3, observa-se que o tempo predominante da prática regular da natação é de um a dois anos $(41,2 \%)$ e que, após, há uma queda. 0 motivo por que ocorre esta diminuição não se sabe ao certo; talvez porque a maioria dessas crianças tenha iniciado a praticar natação exclusivamente por causa da asma e, com a melhora da mesma, tende a abandonar a atividade.

\begin{tabular}{|c|c|}
\hline \multicolumn{2}{|c|}{$\begin{array}{c}\text { TABELA } 3 \\
\text { Distribuição das crianças, segundo tempo } \\
\text { de prática regular da atividade física }\end{array}$} \\
\hline Tempo & № de crianças \\
\hline$<$ de um ano & $4(23,5 \%)$ \\
\hline 1 ano a 2 anos & 7 (41,2\%) \\
\hline$>2$ anos a 3 anos & $3(17,7 \%)$ \\
\hline$>3$ anos a 4 anos & $1 \quad(5,8 \%)$ \\
\hline$>4$ anos & $2(11,8 \%)$ \\
\hline Total & $17(100 \%)$ \\
\hline
\end{tabular}

Observa-se na tabela 4 que a freqüência semanal da prática da natação de duas vezes apresenta um percentual bastante elevado, 82,3\%, que corresponde a 14 crianças. Somente $17,7 \%$, no caso, três crianças, praticam natação três vezes por semana. Das escolas de natação investigadas, somente uma tem opção de três vezes por semana.

TABELA 4
Distribuição das crianças, segundo freqüência
semanal da prática da natação

Este é um motivo que nos leva a refletir, porque a maioria das escolas de natação se utiliza de somente duas vezes semanais de prática da atividade. No entanto, sabe-se que o indicado para uma atividade física aeróbica é de no mínimo três vezes por semana(3).
Através dos dados da tabela 5 pode-se perceber que a influência de outras atividades além da natação é mínima, o que nos leva a constatar que os resultados da pesquisa foram pouco influenciados por outras atividades físicas.

TABELA 5
Distribuição das crianças, segundo a prática de
outra atividade física orientada além da natação

\section{Aspectos relativos aos dados clínicos da asma}

Segundo Marques(10), 80 a $90 \%$ das crianças asmáticas apresentam seus primeiros sintomas antes de quatro a cinco anos de idade.

De acordo com os resultados da tabela 6 , percebe-se que $82,3 \%$ das crianças tiveram sua primeira crise até os cinco anos de idade; assim, há concordância entre os resultados obtidos e os dados da literatura consultada.

\begin{tabular}{|c|c|}
\hline \multicolumn{2}{|c|}{$\begin{array}{c}\text { TABELA } 6 \\
\text { Distribuição das crianças, de acordo } \\
\text { com a idade em que teve a primeira crise }\end{array}$} \\
\hline Idade & № de crianças \\
\hline 1 a 2 anos & $8(47,0 \%)$ \\
\hline 3 a 5 anos & $6(35,3 \%)$ \\
\hline 6 a 8 anos & $3(17,7 \%)$ \\
\hline Total & $17(100 \%)$ \\
\hline
\end{tabular}

\section{TABELA 7}

Distribuição das crianças, com relação a doenças associadas ou conseqüentes da própria doença

\section{Doenças}

№ de crianças

\begin{tabular}{lc} 
Pneumonia & 5 \\
Bronquite & 2 \\
Atópico (rinite-eczema) & 7 \\
Infecções virais & 8 \\
Total & 22 \\
\hline
\end{tabular}

De acordo com Marques(10), a infecção viral das vias respiratórias é um dos fatores mais importantes até quatro a cinco anos de idade.

Para N olte(14), freqüentemente a causa é de origem alérgica, mas outros agentes podem estar presentes. Landau(8) adverte que testes alérgicos podem ser realizados, apesar de seu papel não estar claramente definido. 


\begin{tabular}{|c|c|c|c|}
\hline \multicolumn{4}{|c|}{$\begin{array}{c}\text { QUADRO } 8 \\
\text { Distribuição das crianças, segundo agentes } \\
\text { desencadeadores de crises asmáticas }\end{array}$} \\
\hline Agentes & $\begin{array}{l}\text { №de } \\
\text { crianças }\end{array}$ & Classificação & Resultado \\
\hline Alérgicos & 10 & $\begin{array}{l}\text { Inalantes } \\
\text { Alimentos } \\
\text { Medicamentos }\end{array}$ & $\begin{array}{l}5 \\
3 \\
2\end{array}$ \\
\hline Irritantes & 8 & $\begin{array}{l}\text { Mudança de } \\
\text { temperatura e } \\
\text { umidade } \\
\text { Poluição do ar }\end{array}$ & $\begin{array}{l}8 \\
5\end{array}$ \\
\hline Infecciosos & 8 & & \\
\hline Emocionais & 5 & & \\
\hline Exercício físico & 1 & & \\
\hline
\end{tabular}

Segundo Teixeira( ${ }^{(20)}$, deve-se deixar claro que a sensibilidade geralmente é a mais de um alérgeno.

No caso desta pesquisa, a sensibilidade do asmático foi observada pelas mães.

Conforme a tabela 9, observou-se que dos 17 entrevistados todos têm uma provável predisposição hereditária em relação à asma, sendo que oito crianças apresentaram grau de parentesco próximo: o pai e a mãe. Algumas crianças tinham mais de um parente com história de asma, o que explica o total de 23 casos.

\begin{tabular}{|c|c|c|c|}
\hline \multicolumn{4}{|c|}{ 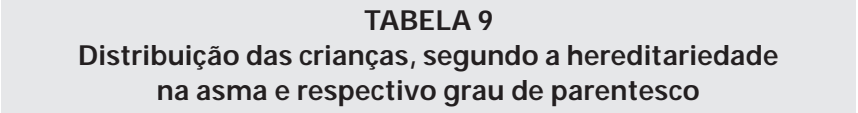 } \\
\hline \multirow[t]{3}{*}{ Sim/Não } & № de crianças & $\begin{array}{c}\text { Grau de } \\
\text { parentesco }\end{array}$ & № de casos \\
\hline & & Mãe & 5 \\
\hline & & Pai & 3 \\
\hline \multirow[t]{3}{*}{ Sim } & 17 & Irmãos & 5 \\
\hline & & Avós & 5 \\
\hline & & Tios & 5 \\
\hline Não & - & - & - \\
\hline Total & 17 & & 23 \\
\hline
\end{tabular}

Clifford et al. (citados por Dinwiddi( ${ }^{4}$ ) observaram filhos de pais asmáticos e constataram que as crianças que têm um dos pais asmáticos possuem o dobro de possibilidade de desenvolver os sintomas da asma, se comparadas à população geral.

Segundo Negreiros ${ }^{(11)}$, parece que as mães asmáticas são mais aptas a transmitir a tendência asmática do que os pais.

Com relação ao exercício físico como agente indutor (tabela 10), percebe-se que quatro crianças já desencadearam crise durante o exercício físico, porém estas mães não po-

dem afirmar se estas crises foram causadas pelo exercício físico especificamente ou por outro agente que tenha influenciado no momento em que estavam em atividade. Somente uma das mães relatou que as duas últimas crises a criança teve brincando no parque da escola e outra jogando bola. Estas crises foram passageiras. Pela característica das crises, supomos que elas tenham sido realmente induzidas pelo exercício, confirmando uma crise de asma induzida pelo exercício (AIE).

\begin{tabular}{lcccc}
\hline \multicolumn{5}{c}{$\begin{array}{c}\text { TABELA } 10 \\
\text { Distribuição das crianças, quanto ao exercício físico, } \\
\text { como desencadeador ou não de crise e em qual situação }\end{array}$} \\
\hline Sim/ Não & $\begin{array}{c}\text { No de } \\
\text { crianças }\end{array}$ & Situação & Freqüência & Resultado \\
& & $\begin{array}{l}\text { Correndo } \\
\text { Nadando }\end{array}$ & 1 & \\
\hline Sim & 4 & $\begin{array}{l}\text { Pedalando } \\
\text { Brincando }\end{array}$ & 1 & 4 \\
\hline Não & 13 & & 13 \\
\hline Total & 17 & & 17 \\
\hline
\end{tabular}

A AIE se caracteriza por um grau de broncoespasmo que varia em diferentes tipos de exercícios, atingindo o grau máximo durante a corrida, sendo menor no ciclismo e ainda menor na natação. A crise se caracteriza inicialmente com broncodilatação, mas após três a cinco minutos começa a broncoconstrição, que atinge seu nível máximo cinco minutos após o exercício; após este período ocorre uma recuperação gradual, geralmente desaparecendo após 20-40 minutos $^{(4,5,17,18)}$.

Percebem-se, na tabela 11, nove crianças com alterações posturais, sendo que em quatro a deformidade postural foi o tórax em quilha (projeção do esterno). Esta é uma alteração típica do asmático.

\section{TABELA 11 \\ Distribuição das crianças, segundo as deformidades posturais}

\section{Deformidade postural}

Tórax em quilha (peito de pombo) Projeção dos ombros para a frente Escoliose e/ou lordose Nenhuma Total

\section{№ de alterações}

4
3
2
8
17

Segundo Lapierre(9), os estados orgânicos deficientes geralmente estão acompanhados de uma insuficiência respiratória; essa insuficiência predispõe o organismo a doenças e deformidades. 
Nas crianças asmáticas as deficiências posturais e deformidades torácicas são conseqüências da dificuldade respiratória e da hipertonia muscular ${ }^{(13)}$.

De acordo com Teixeira ${ }^{(19)}$, as deficiências mais freqüentes nos asmáticos são tórax redondo ("em tonel"), tórax em quilha, horizontalização das costelas e cifose dorsal.

\section{Aspectos relativos aos dados clínicos da asma, cor- relacionados com a prática da natação}

A nalisando os dados da tabela 12 , percebe-se que houve aumento no intervalo entre uma crise e outra. Antes da prática da natação, 47,0\% das crianças tinham crises mais de uma vez por mês.

\section{TABELA 12}

Distribuição das crianças, com relação ao intervalo das crises antes e após a prática da natação

\begin{tabular}{|c|c|c|}
\hline Freqüência & Antes & Após \\
\hline +1 vez por mês & $8(47,0 \%)$ & \\
\hline a cada mês & $4(23,5 \%)$ & \\
\hline a cada 2 meses & $2(11,8 \%)$ & $1 \quad(5,8 \%)$ \\
\hline a cada 3 meses & $3(17,7 \%)$ & $1 \quad(5,8 \%)$ \\
\hline a cada 4 meses & & $3(17,7 \%)$ \\
\hline a cada 6 meses & & $6(35,3 \%)$ \\
\hline a cada ano & & $3(17,7 \%)$ \\
\hline - 1 vez por ano & & $3(17,7 \%)$ \\
\hline Total & $7(100 \%)$ & $7(100 \%)$ \\
\hline
\end{tabular}

O maior período entre uma crise e outra era de três meses, com percentual de $17,7 \%$, que corresponde a três crianças. A pós a prática da natação, percebe-se nítida diferença. 0 percentual maior, que é de $35,3 \%$, corresponde a seis crianças, que passaram a ter crises de seis em seis meses; as crises mais freqüentes são de dois em dois meses, com percentual de 5,8\% - uma criança. Houve casos de crianças em que a freqüência das crises passou a uma vez por ano ou até mesmo a mais de um ano que não a manifestam; estes casos atingiram um percentual de 17,7\%. Também desapareceram os casos de crises mais de uma vez por mês.

Estes resultados são confirmados pela literatura; de acordo com Oliveira(15), existem crianças asmáticas cujas crises, com a prática da natação, tendem a diminuir, podendo até mesmo desaparecer.

Com relação à duração das crises, observou-se predominância de três a seis dias de duração antes de iniciarem a prática da atividade. A pós a prática da natação, percebeuse uma redução dos dias que duram as crises, atingindo um percentual de $76,5 \%$, correspondendo à duração de menos de três dias. Observa-se, também, que após a iniciação da prática desta atividade não houve nenhum caso com duração maior que seis dias; no entanto, antes o percentual era de $29,4 \%$ (tabela 13 ).

\section{TABELA 13}

Distribuição das crianças, com relação à duração das crises antes e após a prática da natação

\begin{tabular}{ccc} 
Duração (em dias) & Antes & Após \\
\hline$<3$ & $3(17,7 \%)$ & $13(76,5 \%)$ \\
\hline 3 a 6 & $9(52,9 \%)$ & $4(23,5 \%)$ \\
\hline > & $5(29,4 \%)$ & - \\
\hline Total & $17(100 \%)$ & $17(100 \%)$ \\
\hline
\end{tabular}

De acordo com pesquisa realizada por Sly et al. ${ }^{(19)} \mathrm{em} 26$ crianças, de nove a 13 anos, das clínicas de alergia pediátrica, todas tinham episódios de crises asmáticas e testes alérgicos positivos. As crianças foram divididas em grupos controle e experimental, sendo que o experimental participou de um programa de atividades físicas por três meses, três vezes semanais, com duas horas de duração cada. As atividades consistiram de uma hora de natação, com ênfase no controle respiratório, e uma hora de exercícios gerais. Os resultados, comparando os grupos, indicam menor número de dias com sibilos que caracterizam o broncoespasmo no grupo experimental.

A tabela 14 procura classificar a intensidade das crises asmáticas, relacionando com a prática da natação.

TABELA 14

Distribuição das crianças, com relação à intensidade das crises antes e após a prática da natação

\begin{tabular}{lccc} 
Intensidade & \multicolumn{1}{c}{ Antes } & Após \\
Leve & $2(11,8 \%)$ & $11(64,7 \%)$ \\
Moderada & $5(29,4 \%)$ & $6(35,3 \%)$ \\
Elevada & $10(58,8 \%)$ & - \\
Total & $17(100 \%)$ & $17(100 \%)$ \\
\hline
\end{tabular}

Percebeu-se que $58,8 \%$ dos casos tinham grau de intensidade grave antes de iniciarem a prática da atividade. As mães relataram que estas crianças tinham crises freqüentes, uma vez por mês, ou até mais, e que a duração era de cinco a seis dias ou até uma semana; por esse motivo, um dos critérios foi relacionar a freqüência e a duração com a intensidade.

Todas estas crianças foram várias vezes à emergência e algumas ficaram internadas, necessitando uso de medicamentos para controlar a crise. Depois da prática da natação, verificou-se que a intensidade das crises que predominou foi a leve, com percentual de $64,7 \%$, e a intensidade moderada aumentou para 35,3\%. Percebe-se que não houve nenhum grau de intensidade elevada. 


\section{CONCLUSÕES E RECOMENDAÇÕES}

Muito se tem dito sobre os benefícios da natação para o asmático; entretanto, pouco tem sido pesquisado cientificamente. Este estudo, embora possua limitações, procurou evidenciar, de modo mais confiável, informações novas acerca do assunto.

O s autores recomendam que outras pesquisas nesta área sejam realizadas, preferencialmente utilizando-se de uma amostra maior e, se possível, controlando outras variáveis, o que não ocorre neste caso.

Sugerimos, por exemplo, uma pesquisa na qual sejam utilizados parâmetros clínicos e laboratoriais, testes de função pulmonar, controlando paralelamente o uso de medicamentos e os fatores desencadeadores das crises. Também, se possível, que seja utilizado grupo-controle e separação por faixas etárias.

\section{REFERÊNCIAS}

1. Azeredo CAC: Fisioterapia respiratória, São Paulo, Panamed, 1984.

2. Carvalho MRA: Fisioterapia respiratória, Curitiba, A theneu, 1987.

3. Cooper KH: O programa aeróbico para o bem-estar total, Rio de J aneiro, Editorial Nórdica, 1982.

4. Dinwiddie R: O diagnóstico e o manejo da doença respiratória pediátrica, Porto Alegre, Artes Médicas, 1992.

5. Fitch KD: Effects of swimming training on children with asthma. Arch Dis Child 51: 190-194, 1976.

6. Grumach AS, Teixeira L: Asmáticos: os exercícios proibidos e os recomendados. Boa Forma 24: 51-52, 1989.
7. Hughes DM, McLeod M, Garner B, Goldbloom RB: Controlled trial of a home and ambulatory program for asthmatic children. Pediatrics 87: 1991.

8. Landau LI: $\mathrm{O}$ tórax; in Levison H: Clínicas Pediátricas da América do Norte, Rio de J aneiro, Interamericana, 1979, p. 581-601.

9. Lapierre A: A reeducação física, São Paulo, Manole, 1982.

10. Marques C: In Reis FJ C, Silva FAA (coord.): Manual de pneumologia pediátrica, Sociedade Brasileira de Pediatria, Rio de J aneiro, 1990, p. 22-61.

11. Negreiros BE: A sma brônquica, in Aloysio de Paula (ed): Pneumologia, São Paulo, Sarvier, 1984.

12. Nickerson BG: Asthmatic patients and those with exercise-induced bronchospasm, in Exercise in Modern Medicine, Baltimore,1989.

13. Nieto P: Educação física e a criança portadora de asma brônquica, USP, 1983.

14. Nolte D: Asma: tratamento precoce e eficaz dos sintomas iniciais: como evitar a asma crônica e suas complicações posteriores, Rio de J aneiro, Ao Livro Técnico, 1983.

15. Oliveira PR: Análise crítica da natação como atividade física capaz de "curar" a asma e a bronquite. Sprint 38: 34-35, 1988.

16. Oliveira PR, Serrano DZ: Natação terapêutica para pneumopatas, São Paulo, Panamed, 1984.

17. Rund DA: Asthma. The Physician and Sportsmedicine 1 (18): 1990.

18. Szentágothai K, Gyene I, Szócska M: Physical exercise program for children with bronchial asthma. Pediatr Pulmonol 3: 166-172, 1987.

19. Teixeira LR: Efeitos de um programa de atividades físicas para crianças asmáticas avaliados por provas de função pulmonar, Dissertação de Mestrado, Escola de Educação Física da U niversidade de São Paulo. São Paulo, 1990.

20. Teixeira $L R$, Teixeira $A L, F r e u d e n h e i m ~ A M$ : Curso de Extensão Universitária em Educação Escolar: Alterações posturais e respiratórias na infância e adolescência, São Paulo, 1991. 